\title{
Study of Serum Vitamin D Level in Different Socio-Demographic Population - A Pilot Study
}

\author{
HOMAYRA TAHSEEN HOSSAIN, ${ }^{1}$ QUAZI TARIKUL ISLAM, ${ }^{2}$ MD. ABUL KASHEM KHANDAKER,${ }^{3}$ HAM NAZMUL AHASAN ${ }^{2}$
}

\begin{abstract}
:
Background: Recently, we see in our clinical practice that many patients who are coming with generalized body aches and pains and diagnosed as fibromyalgia or chronic fatigue, not adequately responding to treatment. When their vitamin D level was done, it was found to be low and correction of their low vitamin D level improved their symptoms dramatically. Despite abundant sunshine in Bangladesh, allowing vitamin D synthesis all the year round, why our people are developing hypovitaminosis D inspired us to do this current study. Our present study is designed to estimate the prevalence of vitamin D deficiency among adult patients presented with aches \& pains as well as to study the association of low vitamin D levels with different socio-demographic parameters.

Methods: A cross sectional observational study was conducted among 212 adult patients aged 18 years and above presented with generalized body aches and pains, attended both outpatient and inpatient departments of Popular Medical College Hospital during the period of March'16-August'16 ( 6 months). Association between vitamin D status \& the individual specific variables was statistically analyzed.

Results: The prevalence of vitamin D deficiency among the study population was found to be100\% in all age groups. Among 212 study population, $73.6 \%$ were female $(n=156) \& 26.4 \%$ were male $(n=56)$. Mean Vitamin $D$ level among male was 14.29 (SD 4.68) \& among female was 12.64 (SD 4.74). The factors associated with severely deficient Vitamin D level were female sex, urban population, \&obesity. It is alarming that $64.2 \%$ of our study population were totally unaware about the importance of sun exposure.

Conclusions: Vitamin D status was associated with a number of socio-demographic variables. Knowledge of these variables may improve targeted education and public health initiatives.
\end{abstract}

Key words: generalized body aches and pains, hypovitaminosis D, socio-demographic parameters.

\section{Introduction:}

Vitamin D has received considerable interest from the medical community and the public at large because of recent evidence for the non-skeletal effects of vitamin D combined with the finding of widespread global deficiency. Vitamin D deficiency is more common than previously thought. It has been estimated that almost 1 billion people in the world suffer from vitamin D deficiency or insufficiency. ${ }^{1}$

Vitamin D has been appreciated for its role in calcium homeostasis and bone health since its identification in

1. Associate Professor, Department of Medicine, Popular Medical College Hospital, Dhaka

2. Professor, Department of Medicine, Popular Medical College Hospital, Dhaka

3. Professor \& Head, Department of Medicine, Popular Medical College Hospital, Dhaka

Corresponding Author: Dr. Homayra Tahseen Hossain, Associate Professor, Department of Medicine, Popular Medical College Hospital, Dhaka. Email: homayra.tahseen@gmail.com.
1921. ${ }^{2}$ While scientists know for decades that vitamin D deficiency leads to bone diseases like rickets \& osteomalacia, recently they have found connections between low vitamin D levels and a wide range of other illnesses, such as diabetes, different type of cancers, autoimmune diseases, psychological disorders like depression, cardiovascular diseases, hypertension, lumbago, pre-eclampsia. ${ }^{3,4}$

Vitamin D is a fat soluble steroid prohormone mainly produced photochemically in the skin from 7 dehydrocholesterol. Vitamin D consists of 2 bioequivalent forms. Vitamin $\mathrm{D}_{2}\left(\mathrm{D}_{2}\right)$, also known as ergocalciferol, is obtained from dietary vegetable sources and oral supplements. Vitamin D3 (D3), also known as cholecalciferol, is obtained primarily from skin exposure to ultraviolet $\mathrm{B}$ (UVB) radiation in sunlight, ingestion of food sources such as oily fish and variably fortified foods (milk, juices, margarines, yogurts, cereals, and soy), and oral supplements. Aside from rich sources such as oily fish, the 
vitamin D content of most foods is between 50 and 200 IU per serving. This value varies greatly by region of the world because fortification markedly improves the availability of vitamin D through diet. Only an estimated $10-20 \%$ of vitamin D is supplied through nutritional intake.5

Both D2 and D3 are biologically inert. Once absorbed from the intestine, they are metabolized in the liver to 25-hydroxyvitamin D [25(OH)D], composed of $25(\mathrm{OH}) \mathrm{D} 2$ and $25(\mathrm{OH}) \mathrm{D} 3$; 25(OH)D (also called calcidiol) is subsequently converted to 1,25-dihydroxyvitamin D [1,25(OH)2D], also known as calcitriol, in the kidney and select other tissues by the action of the $1 \alpha$-hydroxylase enzyme. The predominant effects of vitamin $\mathrm{D}$ are exerted through the endocrine and autocrine actions of calcitriol via activation of the vitamin D receptor in cells.6 The serum levels of $25(\mathrm{OH}) \mathrm{D}$ are measured to determine vitamin D status. Serum $25(\mathrm{OH}) \mathrm{D}$ is considered the best functional indicator of vitamin D status reflecting the sum of cutaneous synthesis and oral intake.7

There is a critical requirement of vitamin $\mathrm{D}$ for bone and mineral homeostasis, and in particular in preventing rickets and osteomalacia. In addition, the vitamin D receptor (VDR) located within the keratinocytes makes these cells a unique photoendocrine vitamin $\mathrm{D}$ system that is stimulated by UVB irradiation.2 Binding of vitamin $\mathrm{D}$ on keratinocyte VDR enhances the production of cathelicidins, which have potent microbicidal activities and are a major component of the innate immune system.8 This argues for an important role of vitamin D in immune defense. Indeed, most tissues and cells in the body express VDRs. Besides its immune-modulatory and anti-inflammatory properties, there is now increasing epidemiological and experimental evidence for a protective effect of vitamin D not only on the risk of fall and fracture but also on dental health, colorectal cancer, hypertension, and cardiovascular mortality. 9 Thus, reaching and maintaining an optimal vitamin $\mathrm{D}$ status at all life stages is of major individual and public health importance.

However, the blood levels of $25(\mathrm{OH}) \mathrm{D}$ that define vitamin $\mathrm{D}$ deficiency remain somewhat controversial.
Currently, most agree that vitamin D concentration below 20 $\mathrm{ng} / \mathrm{ml}$ indicates vitamin $\mathrm{D}$ deficiency, whereas a concentration of $21-29 \mathrm{ng} / \mathrm{ml}$ is considered insufficient, and a 25(OH)D level of $30-100 \mathrm{ng} / \mathrm{ml}$ defines vitamin D sufficiency. 10

Recently, we are observing in our clinical practice that many patients who were coming with generalized body aches and pains and diagnosed as fibromyalgia or chronic fatigue, not adequately responding to treatment. When their vitamin D level was done, it was found to be low and correction of their low vitamin D level improved their symptoms dramatically. Despite abundant sunshine in Bangladesh, allowing vitamin D synthesis all the year round, why our people are developing hypovitaminosis $\mathrm{D}$ striked our mind and inspired us to do this current study. Update data regarding Bangladeshi population are limited. Our present study is designed to estimate the prevalence of vitamin D deficiency among adult patients presented with aches \& pains as well as to study the association of low vitamin D levels with different socio-demographic parameters. The measurement of vitamin D status will provide the opportunity for preventive $\&$ therapeutic interventions.

A number of factors such as duration and time of sun exposure, latitude, season, atmospheric pollution, clothing style, use of sun blocks, skin pigmentation as well as obesity and the presence of several chronic diseases influence the photosynthesis and bioavailability of Vitamin D and contribute to the risk of impaired Vitamin D status of the body.2,11

Public health-awareness campaigns, as well as food fortification with vitamin $\mathrm{D}$ are efficacious and affordable means to prevent vitamin D deficiency.

\section{Methods:}

\section{Study subjects:}

A cross sectional observational study was conducted among the adult patients aged 18 years and above presented with generalized body aches and pains, attended both outpatient and inpatient department of Popular Medical College Hospital during the period of March'16- August'16 ( 6 months). Total 212 adult patients, both male and female were recruited in the study who gave consent after explanation. Following subjects were excluded from the study-

I. $\quad$ Age $<18$ years. 
II. Patients who were not willing to participate in the study.

III. Patients who were taking vitamin D, Calcium with vitamin D or Multivitamins as supplement.

IV. Individuals who suffer from chronic diseases that affect the absorption of Vitamin D such as chronic liver disease $\&$ kidney disease.

V. Subjects who are taking drugs that could influence vitamin D like steroid and anti-epileptics.

The study was approved by the Institutional Ethics Committee. There is no conflict of interest.

\section{Data Collection:}

After taking consent from the individuals fulfilling inclusion criteria of the study, a predesigned structured questionnaire was administered and filled by the doctor attending the patient.The questionnaire recorded socio- demographic characters, clothing style, sunlight exposure, dietary habits, smoking habits, patient's awareness about importance of sun exposure, BMI \& presence of important co-morbidity like diabetes \& hypertension.

Data of total household income were used as indicator of socio-economic status. Average monthly income was reported in 3 categories: Lower class $<20,000$ Taka/ month, middle class 20,000- 50,000 Taka/month \& higher class $>50,000$ Taka/month.

Height of the patient was measured to the nearest $0.1 \mathrm{~cm}$. Weight was measured in light clothing. Body Mass Index (BMI) was calculated as body weight in $\mathrm{Kg}$ divided by squared body height in meters. BMI was then classified as underweight $\left(<18.5 \mathrm{~kg} / \mathrm{m}^{2}\right)$, normal weight (18.5- 24.9 $\left.\mathrm{kg} / \mathrm{m}^{2}\right)$, overweight $\left(25-29.9 \mathrm{~kg} / \mathrm{m}^{2}\right)$ and obesity $\left(\geq 30 \mathrm{~kg} / \mathrm{m}^{2}\right)$ according to the categories of World Health Organization. ${ }^{12}$

\section{Vitamin D analysis:}

The serum $25(\mathrm{OH}) \mathrm{D}$ is the most reliable marker of vitamin D status. So, we measured serum $25(\mathrm{OH})$ D levels of all study participants $\&$ recorded the result in our data collection sheet. Biochemical estimations were carried out using the Architect 25-OH Vitamin D assay which is a quantitative delayed one-step competitive immunoassay. It is used to determine the presence of vitamin $\mathrm{D}$ in human serum and plasma using CMIA technology with flexible assay protocols, referred to as Chemiflex. ${ }^{13}$
We classified participants as normal, vitamin D deficient and insufficient as per recennly available literature. ${ }^{14}$

\begin{tabular}{cc}
\hline $\begin{array}{c}25 \text { Hydroxy vitamin D } \\
(25 \mathrm{OHD}) \text { level }(\mathrm{ng} / \mathrm{ml})\end{array}$ & Interpretation \\
\hline$\geq 30$ & Normal \\
$21-29$ & Insufficient \\
$10-20$ & Deficient \\
$<10$ & Severely deficient \\
\hline
\end{tabular}

\section{Statistical Analysis:}

Statistical analysis was carried out using SPSS 22. Descriptive statistics was carried out. Frequencies are presented for categorical variables. Continuous variables were presented as mean $\pm \mathrm{SD}$. Mean different test (Z-test) was done to find out the association of Vitamin D levels with different socio-demographic factors. A p value $<0.05$ was considered to be statistically significant.

\section{Results:}

A total of 212 adult patients presented with generalized aches and pains were included in the current study. Among 212 study population, $73.6 \%$ were female $(n=156)$ \& $26.4 \%$ were male $(n=56)$. The prevalence of Vitamin D insufficiency among the study population was $100 \%$. Out of the 212 study subjects, $09(4.2 \%)$ were vitamin D insufficient, 147 (68.9\%) were Vitamin D deficient and 56 (26.9\%) were severely Vitamin D deficient (Table-II). Mean Vitamin level among male was 14.29 (SD 4.68) \& among female was 12.64 (SD 4.74). $80 \%$ of the study population belongs to 31-50 years of age range. Mean age of male was 49.7 (age range 18-95) \& female was 45.7 (range 18-80). Lowest mean Vitamin D level was found in the younger age group 18-30 years (mean-12.63, SD 4.62). $95.3 \%$ of study population was Muslim. $64.7 \%$ of female participants were wearing veils (Table I).

Regarding level of education, $08 \%$ of study population was illiterate \& $36.8 \%$ were graduate / post graduate. Level of education was not an important determinant of Vitamin D level in our study. Regarding occupation, $61.7 \%$ of our study population was housewife, $15.1 \%$ were in service (indoor job). Socio-economic status revealed, 85\% $(n=180)$ of study population belongs to middle class. Highest mean Vitamin D level was found among lower socio-economic 
population. $34^{\text {th }}$ of our study population were living in urban location having lower mean Vitamin D level (12.33) than those who were living in rural condition (mean-15.20). All our study subjects were consuming vitamin D enriched food like eggs, fish, milk (except cheese) in different proportion \& amount. It is alarming that only $35.8 \%$ of our study population was somehow aware about the importance of sun exposure, the remaining were totally unaware (Table I).

$46.2 \%$ of our study population were having normal BMI. Their mean vitamin D level was 13.55.; whereas the mean vitamin D level of obese was 11.1. The mean difference between normal and obese population was statistically significant ( $\mathrm{p}$ value 0.007 ). This indicates obesity is an independent risk factor for hypovitaminosis D (Table III). $21.5 \%$ of our study population have been suffering from diabetes \& $34.6 \%$ have been suffering from hypertension (Table IV). Female sex, urban population, overweight \& obesity are associated with severely low level of Vitamin D (Table VI).

\section{Discussion:}

People living in Bangladesh live at a latitude that supports cutaneous vitamin D synthesis all the year round, still hypovitaminosis D is highly prevalent in our country. We did our study to find out the prevalence of hypovitaminosis D among adult patients who presented with generalized aches and pains. We also tried to find out the factors which are associated with low vitamin D level.

It is alarming to find out that the prevalence of vitamin D insufficiency among our study population to be $100 \%$. It indicates that clinicians should routinely think of $\&$ test for vitamin D level in patients with musculoskeletal symptoms, such as bone pain, myalgias and generalized weakness. These symptoms are usually diagnosed and managed as fibromyalgia, chronic fatigue, age related weakness or even depression, ${ }^{15}$ whereas these symptoms are actually due to hypovitaminosis D. Correction of vitamin D level improved these symptoms dramatically. Some studies \& numerous anecdotal observations report vitamin D deficiency in $80 \%$ to $90 \%$ of children \& adults with pain, myalgias \& weakness. ${ }^{16}$

Among 212 study population, 73.6\% were female $(\mathrm{n}=156)$. Mean vitamin D level among male was $14.29 \&$ female was 12.64. So, though both the values are low, mean vitamin $\mathrm{D}$ level of males are higher than that of females. Lack of sun exposure due to staying inside home (61.7\% housewives) and wearing skin covering veils (64.7\% of our female study group wearing veils) are contributing to this low vitamin D levels in females than males.

In our study, hypovitaminosis $\mathrm{D}$ was found in all age groups. Highest percentage of severely deficient vitamin D level $(<10 \mathrm{ng} / \mathrm{ml})$ was found in 31- 50 years of age $(37.5 \%)$. The result is somewhat unexpected since an inverse association between 25OHD and age has been shown in several previous large population based studies. ${ }^{17-19}$ Even if regularly exposed to sunlight, elderly people produce $75 \%$ less cutaneous D3 than young adults. ${ }^{20}$ Our active working age group are suffering from severely low vitamin D level possibly due to lifestyle factors is a striking finding of our study.

In our current study, we found that the people belonging to the lower socio-economic status \& living in rural areas are having higher level of vitamin D - more exposure to sunlight is the contributing factor. About $94 \%$ of our study population was having brown to dark skin complexion. This skin tone with high melanin pigment (natural sunscreen) produces significant lesser amount of vitamin D. ${ }^{21}$

In our study, we found an inverse association between Vitamin D level \& BMI. Association of low vitamin D level \& obesity has been seen in many other studies worldwide. ${ }^{22-24}$ With data from the US 'National Health and Nutrition Examination Survey' (NHANES) Forrest et al. 2011 demonstrated that the risk of having serum $25(\mathrm{OH}) \mathrm{D}$ levels $<50 \mathrm{nmol} / \mathrm{l}$ was about 2 times higher in obese than non-obese persons. ${ }^{25}$ Daly et al. 2012 described that in obese men and women adjusted serum $25(\mathrm{OH}) \mathrm{D}$ levels were $8.3-9.5 \mathrm{nmol} / 1$ lower than in persons with normal weight. ${ }^{26}$ The reasons for the observed lower levels of serum $25(\mathrm{OH}) \mathrm{D}$ among person with higher BMI are still unclear.There are some evidences that vitamin $\mathrm{D}$ is accumulated in adipose tissue with decreased bioavailability and lower serum levels in persons with higher BMI. ${ }^{27}$

Association of 25OHD with glucose regulation and type 2 diabetes has been shown in several studies ${ }^{28}$ including studies done in Finland. ${ }^{29}$ 25OHD level has been associated 
with insulin sensitivity indices, ${ }^{30}$ and low 25OHD has been shown to predict later development of type 2 diabetes. ${ }^{31}$ In our study, $21.5 \%$ of the study population was having diabetes mellitus. One of the most striking finding from our study is the unawareness of the importance of sun exposure among two-third of our study population (64.2\%). If this issue is not addressed properly by public health awareness programme, the huge burden of hypovitaminosis D cannot be combatted.

We recognize some limitations of our study. It was a pilot study with a small sample size of 212. As it was a private Medical College Hospital (mainly outpatient department) based study, sample might not be representative of the total population of our country. Blood samples were collected only once during the month of March-July. It would be useful if study subjects were evaluated at different times of the year to study the seasonal variation. Food intake data were collected by a food frequency questionnaire which does not permit precise estimates of nutrient intake.

\section{Conclusions:}

Despite abundant sunlight in Bangladesh, the prevalence of vitamin D deficiency among adult patients presenting with generalized aches and pains is found to be $100 \%$ across all age groups \& both sexes. Female gender, urbanization, obesity, dark skin complexion, wearing skin covering veils, lifestyle factors (staying inside home/ office/ car- lack of sunlight exposure) - are some of the important factors associated with hypovitaminosis D in Bangladesh.

From the findings of our study, we strongly recommend to screen for vitamin D deficiency who are at risk based on diet, sun exposure, obesity indices, age, sex \& lifestyle factors, as features of hypovitaminosis D are mostly reversible with proper replacement. We also recommend public health efforts in Bangladesh should address the need for vitamin D sufficiency within their population. Increasing awareness about the importance of sun exposure and encouraging the consumption of natural food sources rich in vitamin D, like egg will be helpful. Vitamin D fortification or supplementation may also be viable options to improve the vitamin D status of our population.

Conflict of interest: This study was funded by Bangladesh Society of Medicine (BSM).

\section{Table-I}

Socio-demographic characteristics of the subjects

\begin{tabular}{lcc}
\hline Subject characteristics & $\begin{array}{c}\text { Frequency (n) } \\
\text { Total- 212 }\end{array}$ & $\begin{array}{c}\text { Valid Percen } \\
(\%)\end{array}$ \\
\hline I. Gender distribution: & & \\
a. Male & 56 & 26.4 \\
b. Female & 156 & 73.6
\end{tabular}

II. Age distribution:

$\begin{array}{lll}\text { a. } 18-30 \text { year } & 40 & 19 \\ \text { b. } 31-50 \text { year } & 82 & 39 \\ \text { c. } 51-70 \text { year } & 78 & 36 \\ \text { d. } \geq 70 \text { year } & 12 & 06\end{array}$

III. Religion:

$\begin{array}{lcc}\text { a. Islam } & 202 & 95.3 \\ \text { b. Hindu } & 08 & 3.7 \\ \text { c. Other } & 02 & 1.0\end{array}$

IV. Education

$\begin{array}{llc}\text { a. Illiterate } & 17 & 8.0 \\ \text { b. Primary school } & 36 & 17.0 \\ \text { c. Secondary school } & 39 & 18.4 \\ \begin{array}{l}\text { d. Higher secondary } \\ \begin{array}{l}\text { e. Graduate or post } \\ \text { graduate }\end{array}\end{array} & 42 & 19.8 \\ \end{array}$

V. Occupation
a. Unemployed
b. Housewife
c. Skilled worker
d. Small business
e. Large business
f. Service (indoor job)
15
g. Student
h. Others

VI. Socio-economic status
a. Lower
18
8.4
b. Middle
180
85.04
c. Higher

(1)

6

.




\begin{tabular}{lcc}
\hline Subject characteristics & $\begin{array}{c}\text { Frequency (n) } \\
\text { Total- } 212\end{array}$ & $\begin{array}{c}\text { Valid Percent } \\
(\%)\end{array}$ \\
\hline VII. Locale & 54 & 25.4 \\
a. Rural & 158 & 74.5 \\
b. Urban & & \\
VIII. Skin complexion & 13 & 6.1 \\
a. Fair & 190 & 89.6 \\
b. Brown & 9 & 4.2 \\
c. Dark & & \\
IX. Clothing style (Female) & 101 & 64.7 \\
a. Wearing veil & 55 & 35.3 \\
b. Not wearing veil & & \\
X. Smoking Habit & & 2.8 \\
a. Smoker & 06 & 4.7 \\
b. Ex-smoker & 10 & 92.4 \\
c. Non smoker & 196 & 2.5 \\
XI. Transportation & & 76.6 \\
a. On foot & 06 & 20.9 \\
b. Rickshaw & 162 & \\
c. Motor vehicle/ Bus & 44 & \\
\hline
\end{tabular}

\section{Table-II}

Vitamin D status among the study population (Range: 3.3- 29.0)

\begin{tabular}{cccc}
\hline $\begin{array}{l}\text { Vitamin D } \\
\text { level (ng/ml) }\end{array}$ & $\begin{array}{c}\text { Vitamin D } \\
\text { status }\end{array}$ & Frequency (n) & Percent (\%) \\
\hline$\geq 30$ & Normal & 00 & 00 \\
$21-29.9$ & Insufficient & 09 & 4.2 \\
$10-20.9$ & Deficient & 147 & 68.9 \\
$<10$ & Severely deficient & 56 & 26.9 \\
\hline
\end{tabular}

Table-III

BMI of the study Population

\begin{tabular}{cccc}
\hline BMI & Interpretation & Frequency & Valid \\
& & (n) & Percent (\%) \\
\hline$<18.5$ & Underweight & 14 & 6.6 \\
$18.5-24.9$ & Normal / Healthy & 98 & 46.2 \\
$25-29.9$ & Overweight & 70 & 33.0 \\
$\geq 30$ & Obese & 30 & 14.2 \\
\hline
\end{tabular}

Table-IV

Presence of co-morbidity

\begin{tabular}{ccc}
\hline Co-morbidity & Frequency (n) & Percent (\%) \\
\hline Diabetes & 46 & 21.5 \\
Hypertension & 74 & 34.6 \\
\hline
\end{tabular}

Table-V

Comparison of vitamin D levels with socio-demographic factors

Socio-demographic Frequency Mean (ng/ml) SD $\begin{array}{lll}\text { factors } & \text { (n) } \quad \text { (n) }\end{array}$

\begin{tabular}{|c|c|c|c|}
\hline \multirow[t]{2}{*}{ Sex } & a.Male $(\mathrm{n}=56)$ & 14.29 & 4.68 \\
\hline & b.Female $(n=156)$ & 12.64 & 4.74 \\
\hline \multirow[t]{4}{*}{ Age } & a. $18-30$ year $(n=38)$ & 12.63 & 4.62 \\
\hline & b. $31-50$ year $(n=80)$ & 13.10 & 5.01 \\
\hline & c. $51-70$ year $(n=76)$ & 13.21 & 4.89 \\
\hline & d. $\geq 70$ year $(n=12)$ & 13.80 & 4.02 \\
\hline \multirow{3}{*}{$\begin{array}{c}\text { Socio-economic } \\
\text { status }\end{array}$} & a. Lower $(n=18)$ & 15.0 & 3.67 \\
\hline & b. Middle $(\mathrm{n}=180)$ & 12.74 & 4.92 \\
\hline & c. Higher $(n=14)$ & 14.0 & 4.35 \\
\hline \multirow[t]{2}{*}{ Locale } & a.Rural $(\mathrm{n}=54)$ & 15.20 & 4.50 \\
\hline & b.Urban $(n=158)$ & 12.33 & 4.58 \\
\hline \multirow[t]{4}{*}{ BMI } & a. Normal $(\mathrm{n}=98)$ & 13.55 & 5.12 \\
\hline & b. Underweight $(\mathrm{n}=14)$ & 12.82 & 4.21 \\
\hline & c. Overweight $(\mathrm{n}=70)$ & 13.19 & 4.41 \\
\hline & d. Obese $(n=11.1)$ & 11.10 & 4.71 \\
\hline
\end{tabular}

Table-VI

Factors associated with severely deficient Vitamin D level $(<10 \mathrm{ng} / \mathrm{ml})$

\begin{tabular}{lcc}
\hline Subject characteristics & $\begin{array}{c}\text { Frequency (n) } \\
\text { Total- 56 }\end{array}$ & $\begin{array}{c}\text { Valid Percent } \\
(\%)\end{array}$ \\
\hline Gender: Female & 46 & 82.1 \\
Age group: 31-50 years & 21 & 37.5 \\
Locale: Urban & 52 & 92.8 \\
Socio-economic status: Middle class & 52 & 92.8 \\
BMI: Overweight \& obese & 28 & 50 \\
\hline
\end{tabular}




\section{References:}

01. Masood SH, Iqbal MP, Prevalence of vitamin D in South Asia. Pak J Med Sci, 2008;24(6).

02. Holick MF. Vitamin D deficiency. N England J Med. 2007;357:266-281.

03. Kuryowicz A, Bednarczuk T, Nauman J. The influence of vitamin Ddeficiency on cancers and autoimmune diseases development. Endokrynol Pol 2007;58(2):140-52.

04. Wang TJ, Pencina MJ, Booth SL, Jacqwues PF, Ingelsson E, Lanier K, et al. Vitamin D deficiency and risk of cardiovascular disease. Circulation 2008;29(117):503-11.

05. Pliz S, Vitamin D status and arterial hypertension: A systematic review. Nat. Rev. cardiol. 2009;6:621-630.

06. Plotnikoff GA. Whether or not: the importance of vitamin D status monitoring and supplementation. Minn Med. 2009;92(11):43-46.

07. Thacher TD, Clarke BL. Vitamin D insufficiency. Mayo Clin Proc.2011 Jan;86(1):50-60

08. Zasloff M. Sunlight, vitamin D, and the innate immune defenses of the innate immune defenses of the human skin. $\mathrm{J}$ Invest Dermatol. 2005;125:xvi-xvii.

09. Touvier M, Deschasaux M, Montourcy M et al.Interpretation of plasma PTH concentrations according to 25OHD status, gender, age, weight status and calcium intake: importance of the reference values. J Clin Endocrinol Metab. 2014;99:1196-1203.

10. Lips P, Hosking D, Lippuner K, Norquist JM, Wehren L, Maalouf G, et al Prevalence of vitamin $\mathrm{D}$ inadequacy amongs women with osteoporosis: an International epidemiological investigation. J Intern med. 2006Sep:260(3):245-54. Erratum in: J Intern Med. 2007;261(4):408.

11. Ritu G, Ajay Gupta. Vitamin D deficiency in India: Prevalence, causalities and interventions. Nutrients, February 2014;6:729-775.
12. World Health Organization. Obesity: preventing and managing the global epidemic. Report of a WHO consultation.World Health Organ Tech Rep Ser. 2000;894:i-xii, 1-253.

13. Architect $25-\mathrm{OH}$ vitamin D: Literature

14. Sadat-Ali M, AlElq A, Al-Turki H, Al-Mulhim F, Al-Ali A. Vitamin D levels inhealthy men in eastern Saudi Arabia. Ann Saudi Med 2009;29:378-82.

15. Holick MF. High prevalence of vitamin D inadequacy and implications for health. Mayo Clin Proc. 2006;81:353-373.

16. Plotnikoff GA, Quigley JM. Prevalence of severe hypovitaminosis D in patients with persistent, nonspecific musculoskeletal pain. Mayo Clin Proc. 2003;78:1463-1470.

17. Jorde R, Sneve M, Emaus N, Figenschau Y, Grimnes G. Cross-sectional and longitudinal relation between serum 25-hydroxyvitamin D and body mass index: the Tromsø study. Eur J Nutr 2010;49(7):401-7.

18. Melamed ML, Michos ED, Post W, Astor B. 25-hydroxyvitamin $\mathrm{D}$ levels and the risk of mortality in the general population. Arch Intern Med 2008;168(15):1629-37.

19. Zittermann A, Ernst JB, Gummert JF, Börgermann J. Vitamin D supplementation, body weight and human serum 25-hydroxyvitamin D response: a systematic review. Eur J Nutr 2014 Mar 53(2): 367-74.

20. Lips P. Vitamin D deficiency and secondary hyperparathyroidism in the elderly: consequences for bone loss and fractures and therapeutic implications. Endocr Rev. 2001;22: 477-501.

21. Holick M F. Environmental factors that influence the cutaneous production of vitamin D. Am J Clin Nutr, $1995 ; 61: 638 s-45 s$.

22. Liel Y, Ulmer E, Shary J, Hollis BW, Bell NH. Low circulating vitamin $\mathrm{D}$ in obesity. Calcif Tissue Int 1998;43:199-201.

23. McGill AT, Stewart JM, Lithander FE, Strik CM, Poppitt SD. Relationships of low serum vitamin D3 with anthropometry and markers of the metabolic syndrome and diabetes in overweight and obesity. Nutr J 2008;7:4-8. 
24. Wortsman J, Matsuoka LY, Chen TC, Lu Z, Holick MF. Decreased bioavailability of vitamin D in obesity. Am J Clin Nutr 2000;72: 690-3.

25. Forrest KY, Stuhldreher WL. Prevalence and correlates of vitamin D deficiency in US adults. Nutr Res. 2011;31:48-54.

26. Daly RM, Gagnon C, Lu ZX, Magliano DJ, Dunstan DW, Sikaris KA, et al. Prevalence of vitamin $\mathrm{D}$ deficiency and its determinants in Australian adults aged 25 years and older: a national, population-based study. Clin Endocrinol (Oxf). 2012;77:26-35.

27. Wortsman J, Matsuoka LY, Chen TC, Lu Z, Holick MF. Decreased bioavailability of vitamin D in obesity.Am J ClinNutr. 2000;72:690-3.

28. Forouhi NG, Ye Z, Rickard AP, Khaw KT, Luben $\mathrm{R}$, et al. Circulating 25 -hydroxyvitamin $\mathrm{D}$ concentration and the risk of type 2 diabetes: results from the European Prospective Investigation into Cancer (EPIC)-Norfolk cohort and updated meta-analysis of prospective studies. Diabetologia 2012;55(8):2173-82.

29. Hurskainen AR, Virtanen JK, Tuomainen TP, Nurmi T, Voutilainen S. Association of serum 25-hydroxyvitamin $\mathrm{D}$ with type 2 diabetes and markers of insulin resistance in a general older population in Finland. Diabetes Metab Res Rev 2012;28(5):418-23.

30. Chiu KC, Chu A, Go VL, Saad MF. Hypovitaminosis $\mathrm{D}$ is associated with insulin resistance and beta cell dysfunction. Am J Clin Nutr 2004;79(5):820-5.

31. Pittas AG, Sun Q, Manson JE, Dawson-Hughes B, Hu FB. Plasma 25-hydroxyvitamin D concentration and risk of incident type 2 diabetes in women. Diabetes Care 2010;33(9):2021-3. 